\title{
Optimization of cryoprotectants for Streptococcus thermophilus during freeze-drying using Box-Behnken experimental design of response surface methodology
}

\author{
Guowei Shu'*, Bowen Zhang', Yixin Hui', He Chen', Hongchang Wan ${ }^{2}$ \\ ${ }^{1}$ Depatment of Bioengineering, School of Food and Biological Engineering, Shaanxi University of Science \& Technology, Xi'an 710021 China, \\ ${ }^{2}$ Depatment of Research and Development, Shaanxi Yatai Dairy Co., Ltd., Xianyang, 713701, China
}

\section{A B S TR A C T}

\begin{abstract}
Streptococcus thermophilus are widely used in the production of yogurt as starter culture with L. bulgaricus, maximization of survival of S. thermophilus during freeze-drying is of vital importance in its application. In the present study, the cryoprotectants were optimized to improve the survival of $S$. thermophilus during freeze-drying by Box-Behnken experimental design of Response Surface Methodology. The results showed that, with the mixture of $17 \%(\mathrm{w} / \mathrm{w})$ sucrose, $17 \%(\mathrm{w} / \mathrm{w})$ soluble starch and $0.4 \%(\mathrm{w} / \mathrm{w})$ ascorbic acid. The viability of $S$. thermophilus could be well preserved when freeze-drying was employed. Moreover, the survival rate and viable counts of $S$. thermophilus were observed to $(69.93 \pm 0.07) \%$ and $(2.79 \pm 0.03) \times 10^{11} \mathrm{cfu} / \mathrm{g}$ during freeze-drying with the optimal compound cryprotectants, respectively, which verified the adequacy of predicted value $70.19 \%$ and $2.81 \times 10^{11} \mathrm{cfu} / \mathrm{g}$, which demonstrated that the mixture of the cells in the presence of above three cryprotectants before freeze-drying can protect $S$. thermophilus cells from the adverse freeze-drying environment efficiently.
\end{abstract}

Keywords: Streptococcus thermophilus; Freeze-drying; Cryoprotectants; Box-Behnken experimental design

\section{INTRODUCTION}

Probiotics are microorganisms that, when administered in adequate amounts, confer a health benefit on the host (FAO/WHO, 2001). The commercial significance to the dairy fermentation industry with probiotics, which include cheese, yogurt and sour cream, is recognized worldwide(Carvalho et al., 2004). Streptococcus thermophilus, which are characterized as thermophilic gram-positive microorganism, is widely used for fermented products in combination with Lactobacillus bulgaricus (Gezginc et al., 2013). The beneficial effects of probiotics were ensured by an adequate amount as recommends by the international dairy federation that, the level of probiotics in the products must be $10^{6} \mathrm{cfu} / \mathrm{mL}$ and more when consumption (Sohail et al., 2013). However, the food process and storage challenged and diminished the viability and number of probiotics in the products (Wang et al., 2016). Therefore, consideration of maintaining or enhancing the viability of probiotics, the appropriate methods such as drying processes or encapsulation technology must be taken.

Drying processes, which involve in the transition of microorganisms from aliquid to a solid medium were used in biotechnology industry (Iaconelli et al., 2015). In which, freeze-drying can not only keep yoghurt fresh but maintains a sufficient quantity of viable probiotics (Capela et al., 2006), is proved to be a common way to preserve microorganisms for a long time (Berny and Hennebert, 1991). Freeze-drying is preferred to be a suitable drying technique for the conservation of micro-organisms (Morgan et al., 2006, Stephan et al., 2016). In studies concerning freeze-drying of bacteria, researchers suggested that bacteria belonging to different species and strains may differ in their sensitivity to freeze-drying (Carvalho et al., 2004, Stephan et al., 2016), moreover, survival or viabilities are expressed as a key role that influenced by initial cell concentration, cryoprotectants, rehydration medium and physical aspects during the drying phases of the process

\footnotetext{
*Corresponding author:

Guowei Shu, School of Food and Biological Engineering, Shaanxi University of Science \& Technology, Xi'an 710021 China

E-mail: shuguowei@gmail.com
}

Received: 20 August 2016;

Revised: 12 February 2017;

Accepted: 16 February 2017;

Published Online: 24 February 2017 
(Abadias et al., 2001, DePaz et al., 2002, Carvalho et al., 2003, Capela et al., 2006, Peiren et al., 2016).

Freeze-drying consists of a critical freezing step and a sublimation step, and the cells were dried by remove the ice crystals and bound water during these two steps. However, a number of factors, such as species (Béal and Corrieu, 2000), freeze-drying parameters (Abadias et al., 2001) as well as rehydration conditions (Liu et al., 2003), influence the viability of cells. The decrease of viable cells is probably caused by several reasons. The formation of ice during freeze-drying could damage the cell membrane physically (Béal and Corrieu, 2000), as well as affect the properties of hydrophilic macromolecules with the removal of water in cells (Fowler and Toner, 2005). Furthermore, due to the stability of cell structure and the role in maintaining cell function of bound water, the removal of water will lead to the destruction of cell wall and cell membrane as well as the damage of surface proteins (Allison et al., 1999, DePaz et al., 2002).

Thus, it is crucial to add a variety of protective agents before freeze-drying to maintain the vitality of cells (Schoug et al., 2006). Many compounds have been proved to help the enhancement of survival ability of bacteria cells (Champagne et al., 1991, Yang CY, 2012). It is well documented that carbohydrates have effect on protecting probiotics during freeze-drying, such as trehalose (Fowler and Toner, 2005), sucrose (Carvalho et al., 2003), lactose (Higl et al., 2007, Chen et al., 2015a) and fructooligosaccharides, inulin (Schwab et al., 2007). Moreover, some proteins and antioxidant compounds are reported to have same effect, including skim milk, soy protein, ascorbic acid and L-cysteine (Hubalek, 2003). Besides, some salt buffers (Carvalho et al., 2003), phosphate (Ohtake et al., 2004) are confirmed to be protectants in several studies. Generally, each single protective agent shows advantages during freeze-drying. Therefore, a better effect could be achieved with the mixture of several protectants according to an appropriate formula.

For this proper, response surface methodology was employed as a useful model for investigating the main and combined effects of multiple parameters (Ghobadi et al., 2017), and it is an efficient strategic experimental tool by which the optimal conditions of a multivariable system (Anvari et al., 2014, Chmiel et al., 2017) or optimal cryoprotectant contents may be determined (Chen et al., 2015a), from which a Box-Behnken experimental design can carry out a limited number of experiments.

In our previous work, sucrose, soluble starch and ascorbic acid showed the better effect on protecting Streptococcus thermophilus during freeze-drying by Plackett-Burman design (Chen et al., 2015b). The aim of this study was to optimize the levels of the significant factors(sucrose, soluble starch and ascorbic acid) for cryoprotectants of Streptococcus thermophilus to maximized viable counts as well as survival rate during freeze-drying, and to research the mutural interactions between selected factors using BoxBehnken experimental design.

\section{MATERIALS AND METHODS}

\section{Strain and inoculum preparation}

Streptococcus thermophilus obtained from College of Life Science \& Engineering, Shaanxi University of Science \& Technology were used in this study, and the strain was isolated from commercial yogurt, which was suitable for goat milk fermentation. Streptococcus thermophilus were grown in M17 broth medium with 2\% (v/v) inoculum at $42{ }^{\circ} \mathrm{C}$ for $24 \mathrm{~h}$. On the base of M17 medium, agar (Beijing Abxing Bio-tech Co., Ltd., Beijing, China) $10 \mathrm{~g}$ was added and sterilized at $118{ }^{\circ} \mathrm{C}$ for $15 \mathrm{~min}$ for viable counts of Streptococcus thermophilus.

\section{Preparation of cryoprotectant}

All the candidate cryoprotectants were based on our previous work (Chen et al., 2015b) and formulated into five concentrations with distilled water to form stock solution. In which, sucrose (Beijing Abxing Bio-tech Co., Ltd., Beijing, China) solution were moist-heat sterilized at $115^{\circ} \mathrm{C}$ for $15 \mathrm{~min}$, ascorbic acid (Tianjin Fuchen Chemical Reagent Factory, Tianjin, China) were sterilized with $0.22 \mu \mathrm{m}$ filter membrane and soluble starch (Beijing Abxing Bio-tech Co., Ltd., Beijing, China) were sterilized at $108^{\circ} \mathrm{C}$ for $15 \mathrm{~min}$.

\section{Vacuum freeze-drying}

After activation in triplicate and cultivated in M17 broth at $42^{\circ} \mathrm{C}$ for $11 \mathrm{~h}$, Streptococcus thermophilus were centrifuged for $10 \mathrm{~min}$ at $8000 \mathrm{r} / \mathrm{min}$ to the remaining bacteria. Then the cells were pre-frozen at $-80^{\circ} \mathrm{C}$ for $8 \mathrm{~h}$ after cryoprotectants and buffer phosphate that kept equivalent were added, and then frozen using a vacuum freeze dryer (FD-1D -50, Beijing Boyikang Laboratory Instruments Co., Ltd., Beijing, China).

\section{Virable counts}

After a serial ten-fold dilution of Streptococcus thermophiles cells with sterilized $0.1 \%(\mathrm{w} / \mathrm{v})$ peptone solution, the suitable concentration diluted bacterial suspension $0.1 \mathrm{~mL}$ with a syring was coated uniformly on $\mathrm{M} 17$ cooled at $50^{\circ} \mathrm{C}$. Then the plates were carried out at $37^{\circ} \mathrm{C}$ for $48 \mathrm{~h}$, and the viable counts of Streptococcus thermophilus were in triplicate. The freeze-dried powder was recovered with sterilized peptone (Beijing Aobxing Bio-tech Co., Ltd., Beijing, 
China) solution to bacterial suspension, then diluted to the pre-freeze dried volumes $(\mathrm{mL})$ and the variable counts $(\mathrm{cfu} / \mathrm{mL})$ were determined as above. All the experiments were carried out in three replicates.

\section{Calculation of survival}

Survival of bacterial cells after freeze-dried were determined by the equation (Ampatzoglou et al., 2010, Chen et al., 2015a):

Survial $(\%)=$

$\frac{\text { Viable counts after freeze-drying }(\mathrm{cfu} / \mathrm{ml})}{\text { Viable counts before freeze-drying }(\mathrm{cfu} / \mathrm{ml})} \times 100 \%$

Box-Behnken design and response surface optimization Based on the previous study by Plackett-Burman method and results of climbing test of the main factors (Chen et al., 2015b), we observed that sucrose, soluble starch and ascorbic acid were more effectively when used as cryoprotectants during freeze-drying. Thus the three-levelthree-factor Box-Behnken Design (BBD) of Response Surface Methodology (RSM) was used to the further optimization studies according to the direction and magnitude of the effect of each factor. This methodology is used to optimize all the variables by determining the maximum response values. The factors levels are given in Table 1. The RSM is used to determine the maximum response value as well as evaluate of the main effects and interaction effects. The response values were fitted to a quadratic model after the results performed by the software (SAS, Statistical Analysis System). The quadratic equation which explained the behavior of the system was as follows:

$$
Y=\beta^{\circ}+\sum \beta^{i^{\chi_{j}}}+\beta^{\mathrm{in}_{j}^{\chi_{j}}}+\beta^{\mathrm{ij} \chi_{\mathrm{i}} \chi_{j}}
$$

Where: $Y$ is the predicted responses of the dependent variable, $X$ are independent variables, $\beta_{0}, \beta_{i}, \beta_{i p} \beta_{i j}$ are the second-order reaction constant, the linear coefficient, the quadratic coefficient and regression coefficient of interactions between two independent variables, respectively.

\section{Statistical analysis of the data}

SAS (Statistical Analysis System, SAS INSTITUTE INC. USA, Version 9.1) software was used for the regression

Table 1: The coded levels of each factors including sucrose, soluble starch, ascorbic acid for Box-Behnken experimental design

\begin{tabular}{lccc}
\hline Factors (\%) & \multicolumn{3}{c}{ Coded levels } \\
\cline { 2 - 4 } & $-\mathbf{1}$ & $\mathbf{0}$ & $\mathbf{1}$ \\
\hline Sucrose & 16 & 17 & 18 \\
Soluble starch & 16 & 17 & 18 \\
Ascorbic acid & 0.35 & 0.4 & 0.45 \\
\hline
\end{tabular}

analysis of the experimental data by establishing quadratic regression equation. Besides, the three-dimensional surface plots which indicated the effect of variables on the desirability were constructed using SAS, standard deviation was performed to compare differences in the mean of the values.

\section{RESULTS}

The experimental design and results of Box-Behnken The RSM was used to determine the optimum concentrations of the three key factors. BBD was involved in this study. The experiment design and results are shown in Table 2. Survival rate of Streptococcus thermophilus was represented by $\mathrm{Y}_{1}(\%)$ and the viable counts of freeze-dried powder was represented by $\mathrm{Y}_{2}\left(\times 10^{11} \mathrm{cfu} / \mathrm{g}\right)$.

\section{Regression analysis}

According to the results of $\mathrm{BBD}$, the data were analyzed by the quadratic regression model using SAS to obtain the regression equation. Analysis of variance (ANOVA) was used to test the significance of coefficient.

$\mathrm{Y}_{1}=70.19+1.14 \mathrm{X}_{1}-1.96 \mathrm{X}_{2}+0.65 \mathrm{X}_{3}-$ $11.12 \mathrm{X}_{1}{ }^{2}+0.41 \mathrm{X}_{1} \mathrm{X}_{2}+0.41 \mathrm{X}_{1} \mathrm{X}_{3}-10.96 \mathrm{X}_{2}{ }^{2}-3.84 \mathrm{X}_{2} \mathrm{X}_{3}-$ $14.87 \mathrm{X}_{3}^{2}$

$\mathrm{Y}_{2}=2.85+0.089 \mathrm{X}_{1}-0.079 \mathrm{X}_{2}+0.078 \mathrm{X}_{3}-0.376 \mathrm{X}_{1}{ }^{2}-0.065 \mathrm{X}_{1} \mathrm{X}_{2}$ $0.008 \mathrm{X}_{1} \mathrm{X}_{3}-0.316 \mathrm{X}_{2}^{2}-0.293 \mathrm{X}_{2} \mathrm{X}_{3}-0.638 \mathrm{X}_{3}^{2}$

Where: $\mathrm{Y}_{1}$ and $\mathrm{Y}_{2}$ are the desirability value of survival rate of Streptococcus thermophilus and viable counts of fungus powder. $\mathrm{X}_{1}, \mathrm{X}_{2}, \mathrm{X}_{3}$ are the coded values of the test variables soluble starch, sucrose and ascorbic acid, respectively.

\begin{tabular}{|c|c|c|c|c|c|}
\hline Runs & $\mathrm{X} 1$ & $\mathrm{X} 2$ & X3 & Y1\% & $\begin{array}{c}\text { Y2 } \\
\left(\times 10^{11} \mathrm{cfu} / \mathrm{g}\right)\end{array}$ \\
\hline 1 & -1 & -1 & 0 & 51.96 & 2.24 \\
\hline 2 & -1 & 1 & 0 & 46.08 & 2.14 \\
\hline 3 & 1 & -1 & 0 & 49.34 & 2.3 \\
\hline 4 & 1 & 1 & 0 & 45.10 & 1.94 \\
\hline 5 & 0 & -1 & -1 & 38.89 & 1.44 \\
\hline 6 & 0 & -1 & 1 & 52.62 & 2.43 \\
\hline 7 & 0 & 1 & -1 & 43.79 & 1.94 \\
\hline 8 & 0 & 1 & 1 & 42.16 & 1.76 \\
\hline 9 & -1 & 0 & -1 & 43.14 & 1.66 \\
\hline 10 & 1 & 0 & -1 & 48.70 & 2.10 \\
\hline 11 & -1 & 0 & 1 & 38.89 & 1.58 \\
\hline 12 & 1 & 0 & 1 & 46.08 & 1.99 \\
\hline 13 & 0 & 0 & 0 & 72.55 & 2.85 \\
\hline 14 & 0 & 0 & 0 & 68.63 & 2.76 \\
\hline 15 & 0 & 0 & 0 & 69.40 & 2.93 \\
\hline
\end{tabular}


The effect of each variable on response value $\mathrm{Y}_{1}$ and $\mathrm{Y}_{2}$ was determined by the F-test. The results are shown in Table 3.

In Table 3 , the response value $\mathrm{Y}_{1}$ showed a high significance for regression equation $(p=0.011<0.05)$ as well as insignificance for the lack of fit $(p=0.141>0.05)$, which indicated the effectiveness of regression analysis. Furthermore, a value of determination coefficient $\left(\mathrm{R}^{2}=94.7 \%\right)$ was calculated, which indicated that $94.7 \%$ of the response value could be explained by the second-order polynomial predicted equation given above, and the value of adjusted determination coefficient $\left(A d j \mathrm{R}^{2}=85.15 \%\right)$ that

\begin{tabular}{|c|c|c|c|c|c|c|}
\hline Source & DF & SS & MS & $F$ & $p(\mathrm{Pr}>\mathrm{F})$ & Sig \\
\hline \multicolumn{7}{|l|}{ Survival rate } \\
\hline $\mathrm{X} 1$ & 1 & 10.465 & 10.465 & 0.584 & 0.479 & \\
\hline $\mathrm{x} 2$ & 1 & 30.733 & 30.733 & 1.715 & 0.247 & \\
\hline X3 & 1 & 3.419 & 3.419 & 0.191 & 0.681 & \\
\hline $\mathrm{X} 1{ }^{*} \mathrm{X} 1$ & 1 & 456.399 & 456.399 & 25.462 & 0.004 & $* *$ \\
\hline $\mathrm{X} 1{ }^{*} \mathrm{X} 2$ & 1 & 0.674 & 0.674 & 0.038 & 0.854 & \\
\hline $\mathrm{X} 1{ }^{*} \mathrm{X} 3$ & 1 & 0.664 & 0.664 & 0.037 & 0.855 & \\
\hline$X 2 * X 2$ & 1 & 443.155 & 443.155 & 24.723 & 0.004 & $* *$ \\
\hline $\mathrm{X} 2{ }^{*} \mathrm{X} 3$ & 1 & 58.982 & 58.982 & 3.291 & 0.129 & \\
\hline $\mathrm{X} 3^{*} \times 3$ & 1 & 816.752 & 816.752 & 45.565 & 0.001 & $* *$ \\
\hline Model & 9 & 1600.261 & 177.807 & 9.920 & 0.011 & $*$ \\
\hline (Linear) & 3 & 44.617 & 14.872 & 0.830 & 0.532 & \\
\hline (Quadratic) & 3 & 1495.325 & 498.442 & 27.807 & 0.002 & ** \\
\hline $\begin{array}{l}\text { (Cross } \\
\text { product) }\end{array}$ & 3 & 60.319 & 20.106 & 1.122 & 0.423 & \\
\hline Error & 5 & 89.624 & 17.925 & & & \\
\hline (Lack of fit) & 3 & 80.997 & 26.999 & 6.259 & 0.141 & \\
\hline (Pure error) & 2 & 8.627 & 4.314 & & & \\
\hline Total & 14 & 1689.885 & & & & \\
\hline \multicolumn{7}{|l|}{ Viable counts } \\
\hline $\mathrm{X} 1$ & 1 & 0.063 & 0.063 & 1.156 & 0.331 & \\
\hline $\mathrm{X} 2$ & 1 & 0.050 & 0.050 & 0.910 & 0.384 & \\
\hline X3 & 1 & 0.048 & 0.048 & 0.882 & 0.391 & \\
\hline$X 1{ }^{*} X 1$ & 1 & 0.522 & 0.522 & 0.570 & 0.027 & * \\
\hline$X 1{ }^{*} X 2$ & 1 & 0.017 & 0.017 & 0.310 & 0.602 & \\
\hline $\mathrm{X} 1{ }^{*} \mathrm{X} 3$ & 1 & 0.000 & 0.000 & 0.004 & 0.951 & \\
\hline $\mathrm{X} 2{ }^{*} \mathrm{X} 2$ & 1 & 0.368 & 0.368 & 6.758 & 0.048 & * \\
\hline$X 2{ }^{*} \times 3$ & 1 & 0.342 & 0.342 & 6.280 & 0.054 & \\
\hline$X 3^{*} \times 3$ & 1 & 1.505 & 1.505 & 27.606 & 0.003 & $* *$ \\
\hline Model & 9 & 2.642 & 0.294 & 5.387 & 0.039 & * \\
\hline (Linear) & 3 & 0.161 & 0.054 & 0.983 & 0.471 & \\
\hline (Quadratic) & 3 & 2.122 & 0.707 & 12.980 & 0.009 & $* *$ \\
\hline $\begin{array}{l}\text { (Cross } \\
\text { product) }\end{array}$ & 3 & 0.359 & 0.120 & 2.198 & 0.207 & \\
\hline Error & 5 & 0.272 & 0.054 & & & \\
\hline (Lack of fit) & 3 & 0.258 & 0.086 & 11.890 & 0.079 & \\
\hline (Pure error) & 2 & 0.014 & 0.007 & & & \\
\hline Total & 14 & 2.915 & & & & \\
\hline
\end{tabular}

${ }^{* *} \mathrm{P}<0.01$, very significant; ${ }^{*} \mathrm{P}<0.05$, significant, DF refers to degrees of freedom, SS refers to sum of squares, MS refers to mean square, $F$ and $\mathrm{Pr}>\mathrm{F}$ refer to $\mathrm{F}$ and $\mathrm{P}$ values, respectively was close to the determination coefficient confirmed the high reliability of regression equation. Besides, the high $\mathrm{F}$ value of quadratic $\mathrm{X}_{1}^{2}, \mathrm{X}_{2}^{2}$ and $\mathrm{X}_{3}^{2}$ indicated that there was not a simple linear correlation between the variables and responses. While the low $\mathrm{F}$ value of cross product $\mathrm{X}_{1}$ and $\mathrm{X}_{2}, \mathrm{X}_{1}$ and $\mathrm{X}_{3}, \mathrm{X}_{2}$ and $\mathrm{X}_{3}$ implied there was weak mutual interaction between them.

Furthermore, response value $\mathrm{Y}_{2}$ which showed significance for regression equation $(p=0.039<0.05)$ and insignificance for the lack of fit $(p=0.079>0.05)$ was confirmed effective. And the goodness of the equation was expressed by the determination coefficient $\left(\mathrm{R}^{2}=90.65 \%\right)$ and adjusted determination coefficient $\left(A d j \mathrm{R}^{2}=73.82 \%\right)$ that closed to $\mathrm{R}^{2}$ implied $73.82 \%$ fitting degree. The high $\mathrm{F}$ value of $\mathrm{X}_{1}^{2}, \mathrm{X}_{2}^{2}$ and $\mathrm{X}_{3}^{2}$ showed that there was not a simple linear correlation between each variables and responses. $\mathrm{X}_{2}$ and $\mathrm{X}_{3}$, which had a high $\mathrm{F}$ value, showed significant mutual interaction, while $\mathrm{X}_{1}$ and $\mathrm{X}_{2}, \mathrm{X}_{1}$ and $\mathrm{X}_{3}$ showed weak mutual interaction with low $\mathrm{F}$ value.

The trend of response value $\mathrm{Y}_{1}$ and $\mathrm{Y}_{2}$ affected by factors were shown at Fig. 1. The 95\% prediction intervals showed the three factors had positive effects on the survival rate as well as the viable counts in a certain concentration range. As is shown, the corresponding variables $\mathrm{Y}_{1}$ and $\mathrm{Y}_{2}$ increased primarily and then decreased followed the increase of sucrose $\left(\mathrm{X}_{1}\right)$. With the increasing of soluble starch $\left(\mathrm{X}_{2}\right)$, the response value $Y_{1}$ and $Y_{2}$ were of trend that increased gradually and decreased sharply after reaching to maximum. Ascorbic acid $\left(X_{3}\right)$ showed positive effect to $Y_{1}$ and $Y_{2}$ first,

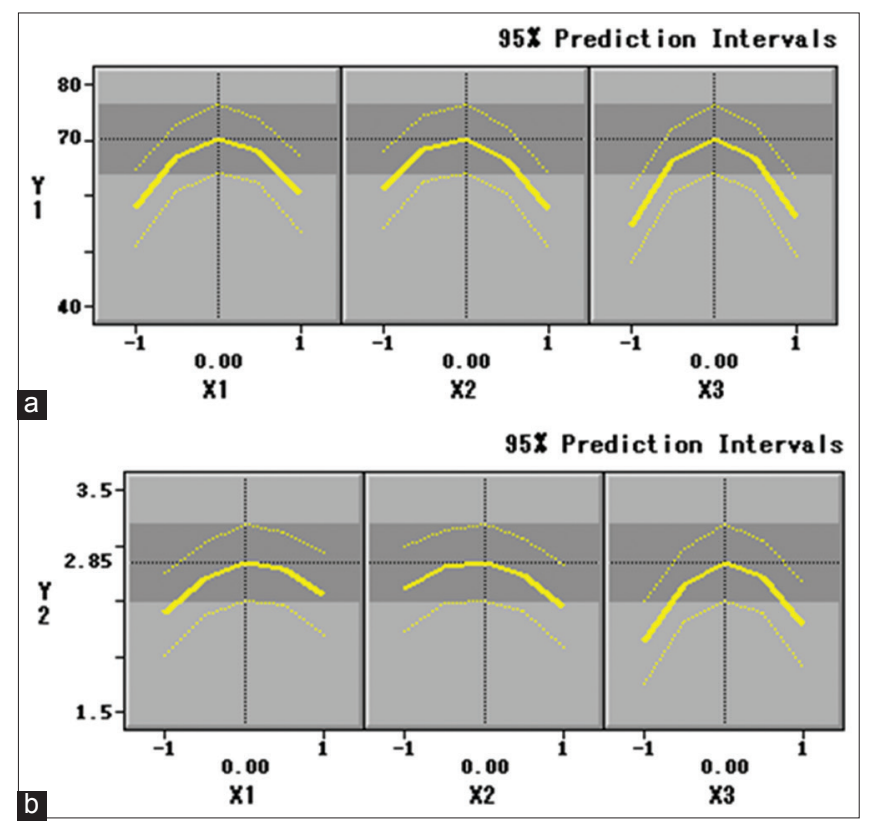

Fig 1. The trends of survival rate (\%) (a) and viable counts $(\times 1011 \mathrm{cfu} / \mathrm{g})$ (b) with sucrose, soluble starch, ascorbic acid, respectively (in order from left to right). 
and both two responses decreased on same change rate with the continuous increasing of concentration.

Three-dimensional response surface and contour plots were generated to obtain a better study of the interactive effects of the three factors to the corresponding variables (Figs. 2 and 3). As Fig. 2 shown, the contour plots seemed to be a circle, it implied that the mutual interaction of $\mathrm{X}_{1} * \mathrm{X}_{2}, \mathrm{X} 1 * \mathrm{X}_{3}, \mathrm{X}_{2} * \mathrm{X}_{3}$ was not significant for the survival rate of Streptococcus thermophiles $\left(\mathrm{Y}_{1}\right)$. Fig. 3 indicated that $\mathrm{X}_{1} * \mathrm{X}_{2}, \mathrm{X}_{1} * \mathrm{X}_{3}$ showed insignificant mutual interaction for the variable counts $\left(\mathrm{Y}_{2}\right)$ which their contour plots were like a circle, while the oval contour plots of $\mathrm{X}_{2} * \mathrm{X}_{3}$ stated that the interaction effect on the response value $\mathrm{Y}_{2}$ was significant. Furthermore, the regression equation $\mathrm{Y}_{1}$ was analyzed using SAS software $\left(\mathrm{Y}_{2}\right.$ as a reference), the maximum value of the responses was obtained at $17 \mathrm{~g} / 100 \mathrm{~mL}$ sucrose, $17 \mathrm{~g} / 100 \mathrm{~mL}$ soluble starch and $0.4 \mathrm{~g} / \mathrm{mL}$ ascorbic acid.
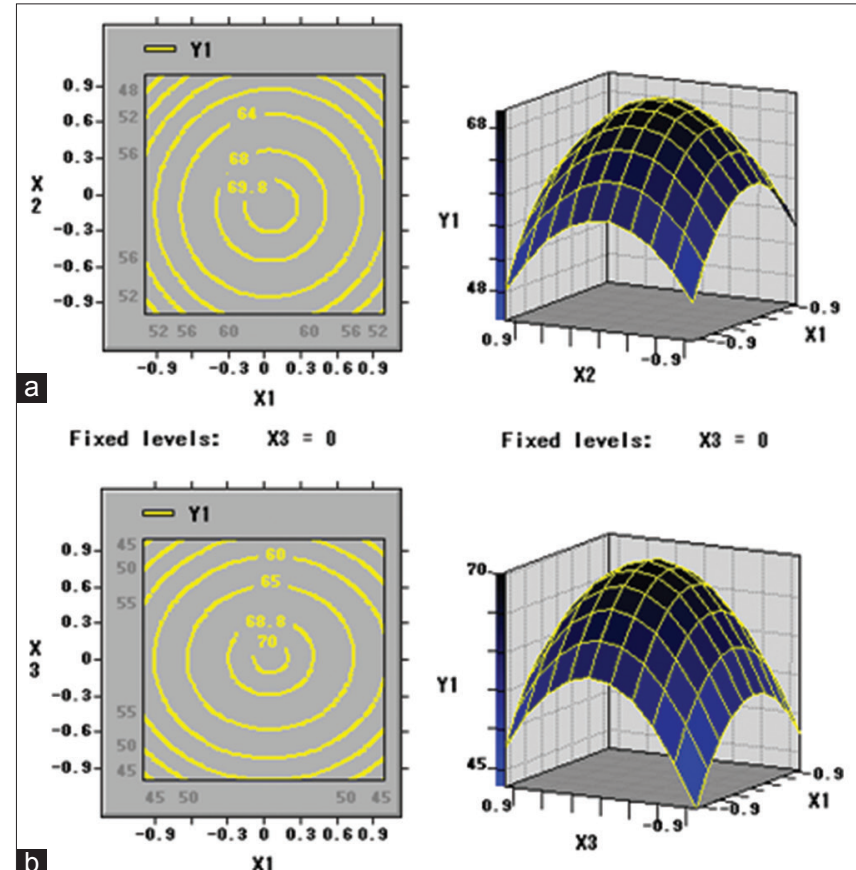

Fixed levels: $\quad X_{3}=0$

$\mathrm{X} 1$

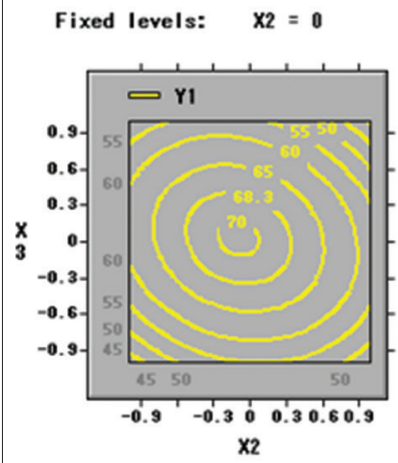

Fixed levels: $\quad X_{1}=0$

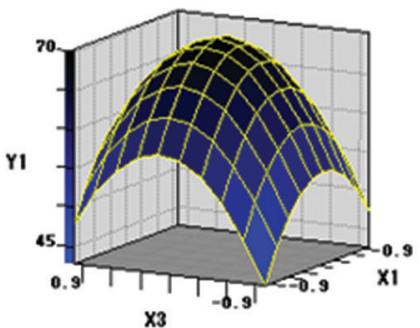

Fixed levels: $\quad X 2=0$

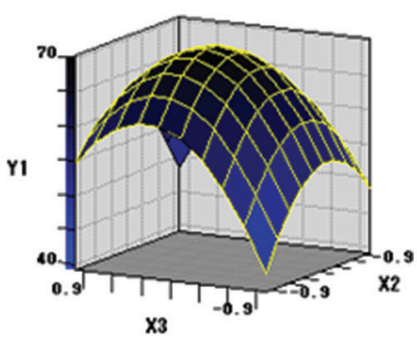

Fixed levels: $\quad x_{1}=\mathbf{0}$

Fig 2. Response surface (Right) and contour (left) plots of sucrose (X1) and soluble starch (X2) (a), sucrose (X1) and ascorbic acid (X3) (b), soluble starch (X2) and ascorbic acid (X3) (c) to survival rate (Y1).

The suitability of the model equation for predicting the optimal response value was tested by a verification experiment additional independent experiments under the previous operational conditions. Consequently, compared the survival rate and viable counts of freeze-dried powder with control $\left(4.13 \%, 2 \times 10^{9} \mathrm{cfu} / \mathrm{g}\right.$, respectively), the responses were increased significantly to $(69.93 \pm 0.07) \%$ and $(2.79 \pm 0.03) \times 10^{11} \mathrm{cfu} / \mathrm{g}$, respectively.

\section{DISCUSSION}

In the present study, we investigated the potential of three subtracts as cryoprotectants to formulate bacteria of the genus Streptococcus thermophiles during freeze-drying. Among these protective agents, sugars are supposed to be preferable due to their relatively low prices, chemically innocuous nature as well as their common use in foods

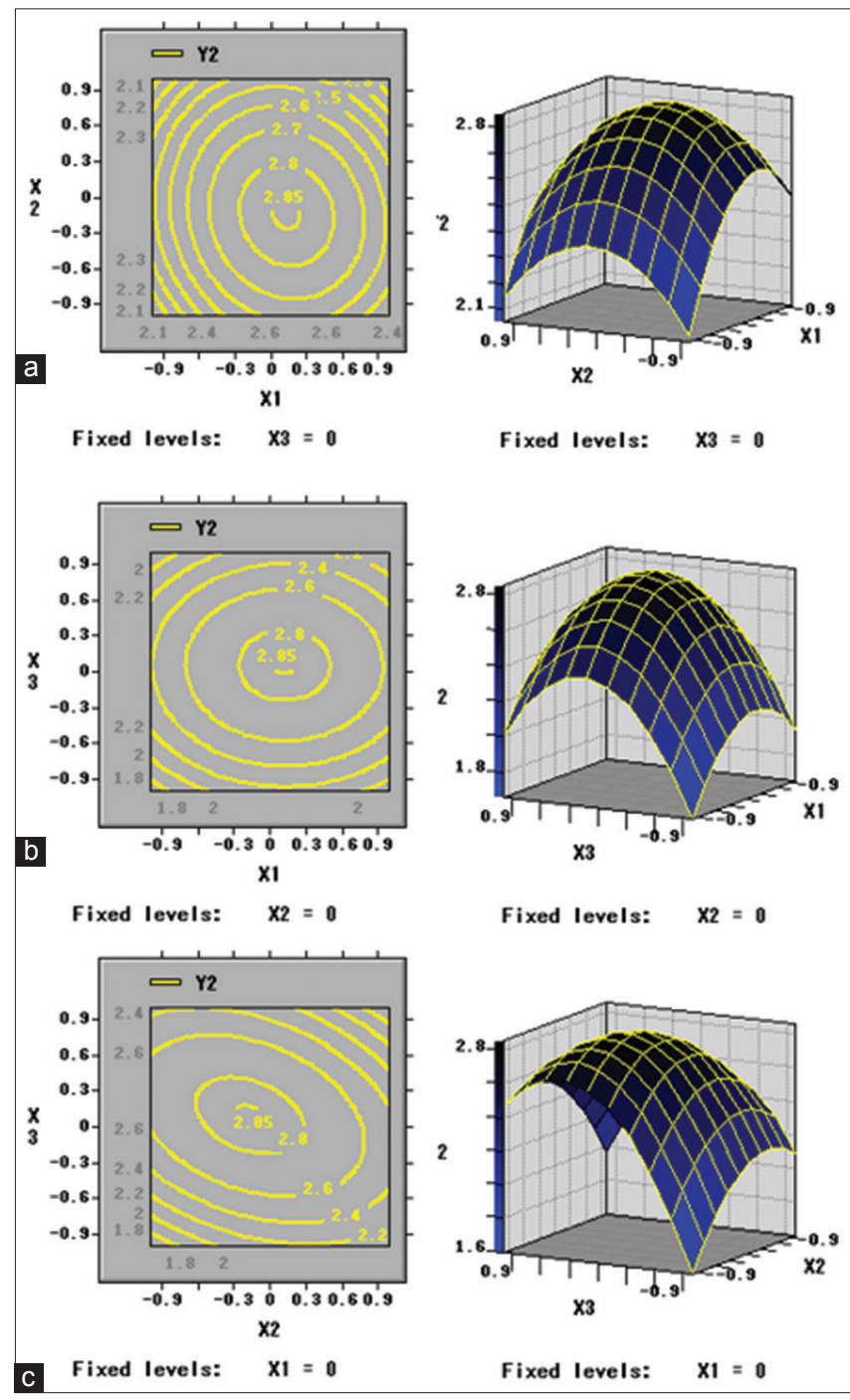

Fig 3. Response surface (Right) and contour (left) plots of sucrose (X1) and soluble starch (X2) (a), sucrose (X1) and ascorbic acid (X3) (b), soluble starch (X2) and ascorbic acid (X3) (c) to viable counts (Y2). 
(Santivarangkna et al., 2008). Selwal et al. (2011) have reported that the mixture of $10 \%$ lactose, $10 \%$ sucrose, skim milk containing $0.5 \%$ yeast extract and $1 \%$ sorbitol and skim milk with $7 \%$ sucrose, $1 \mathrm{M}$ mono-sodium glutamate and $1.5 \%$ gelatin showed significant effect culture on the preservation of Streptococcus thermophiles during freeze-drying (survival rate obtained with $89.9 \%$ ). The protective effect of sucrose was also observed in the protection of Streptococcus lactis mixing with soybean meal, glycerol and mannitol (Zhang et al., 2012). Furthermore, a long-term survival of Lactococcus lactis ssp. lactis after freeze-drying was observed in the presence of sucrose (Chavarri et al., 1988).It was suggested that, by raising the glass-phase transition temperature, sugars can protect lactic acid bacteria cells to reaching the glassy phase without nucleating intracellular ice, it implied that, sugars, especially trehalose and sucrose, play a critical role in maintaining the cytoplasmic membrane properties stably during freeze drying (Panoff et al., 1994, Carvalho et al., 2003, Passot et al., 2015). Additionally, during dry-process, sugars were also suggested to perform desiccation tolerance by forming hydrogen bonds to proteins so that the tertiary protein structure was maintained in the absence of water (Leslie et al., 1995).

Despite the sugars can strongly enhance the viability by acting as a substitute to water through the hydrogen bonds to proteins and cell membrane, other factors such as oxidation can be toxic to the microorganisms during storage time. Damage of oxide to cells could be caused by membrane lipid oxidation, undermine cellular integrity and resulting in leakage of intracellular material, which led to a loss of viability in the process of storage after freeze-drying (Castro et al., 1995). Thus, ascorbic acid was selected to be a protect agents from damage of oxidation and showed an efficient impact on the cells in our study. The protective effect of ascorbic acid had been demonstrated on Lactobacillus bulgaricus (Teixeira et al., 1995) during storage. It had been observed that the presence of ascorbate could reduce the detrimental effect of atmospheric oxygen on Lactobacillus acidophilus (Kurtmann et al., 2009).

Addition of soluble starch to the cells during freeze-drying had been reported to have protective effect on Lactobacillus acidophilus (Qin et al., 2013). While Huang et al. (Huang et al., 2005) demonstrated that soluble starch did not show the impact on the preservation of Lactobacillus delbrueckii subsp. bulgaricus and Streptococcus sativarius subsp. thermophiles. This may be caused by the distinction between species or the formation of clots in soluble starch solution after sterilization, which leads to the inactivation of bacterial cells during freeze-drying. We speculate that soluble starch may be bonded to or inserted into the cell wall mesh structure by hydrogen bonds or unknown cross-linkage to peptidoglycan, or wrapped around the cell peptidoglycan sacculus, which protect the cell from physical damage caused by ice crystals.

\section{CONCLUSIONS}

According to the survival information of Streptococcus thermophiles during freeze-drying, the BoxBehnken Design was used to determine optimal cryoprotectants for the high viability of this bacterium. This study demonstrated that RSM was useful in evaluating the effects of factors leading to a higher survival of the cells. Sucrose, soluble starch and ascorbic acid were efficiently elevated the viability of Streptococcus thermophiles in the freeze-drying process. Through verification experiment, we ascertained that the optimized cryoprotectants gave higher counts of viable cells. It was shown that the response values were $(69.93 \pm 0.07) \%$ and $(2.79 \pm 0.03) \times 10^{11} \mathrm{cfu} / \mathrm{g}$ in average, which was closed to the predicted value.

\section{ACKNOWLEDGEMENT}

The work was partly supported by the Science and Technology Overall Planning for Innovation Engineering Project of Shaanxi Province (No.2016KTZDNY02-03), Collaborative innovation project of Shaanxi Province (No. 2016XT-17), Shaanxi Innovation and Transformation Project of Agricultural Science and Technology (No.NYKJ-2015-004).

\section{Author's contributions}

B. Z. wrote the article and corrected it. H. C., G. S. and H.W. designed the study. B. Z. and Y. H. conducted the experimental work.

\section{REFERENCES}

Abadias, M., A. Benabarre, N. Teixido, J. Usall and I. Vinas. 2001. Effect of freeze drying and protectants on viability of the biocontrol yeast Candida sake. Int. J. Food Microbiol. 65: 173-182.

Allison, S. D., B. Chang, T. W. Randolph and J. F. Carpenter. 1999. Hydrogen bonding between sugar and protein is responsible for inhibition of dehydration-induced protein unfolding. Arch. Biochem. Biophys. 365: 289-298.

Ampatzoglou, A., B. Schurr, G. Deepika, S. Baipong and D. Charalampopoulos. 2010. Influence of fermentation on the acid tolerance and freeze drying survival of Lactobacillus rhamnosus GG. Biochem. Eng. J. 52: 65-70.

Anvari, M., G. Khayati and S. Rostami. 2014. Optimisation of medium composition for probiotic biomass production using response surface methodology. J. Dairy Res. 81: 59-64.

Béal, C. and G. Corrieu. 2000. Method of quantifying the loss of acidification activity of lactic acid starters during freezing and frozen storage. J. Dairy Res. 67: 83-90.

Berny, J. F. and G. L. Hennebert. 1991. Viability and stability of 
yeast-cells and filamentous fungus spores during freezedrying - effects of protectants and cooling rates. Mycologia. 83: 805-815.

Capela, P., T. K. Hay and N. P. Shah. 2006. Effect of cryoprotectants, prebiotics and microencapsulation on survival of probiotic organisms in yoghurt and freeze-dried yoghurt. Food Res. Int. 39: 203-211.

Carvalho, A., J. Silva, P. Ho, P. Teixeira, F. Malcata and P. Gibbs. 2003. Effects of addition of sucrose and salt, and of starvation upon thermotolerance and survival during storage of freezedried Lactobacillus delbrueckii ssp bulgaricus. J. Food Sci. 68: 2538-2541.

Carvalho, A., J. Silva, P. Ho, P. Teixeira, F. Malcata and P. Gibbs. 2004. Relevant factors for the preparation of freeze-dried lactic acid bacteria. Int. Dairy J. 14: 835-847.

Castro, H. P., P. M. Teixeira and R. Kirby. 1995. Storage of lyophilized cultures of Lactobacillus bulgaricus under different relative humidities and atmospheres. Appl. Microbiol. Biotechnol. 44: 172-176.

Champagne, C. P., H. Detournay and M. J. Hardy. 1991. Effect of medium on growth and subsequent survival, after freeze-drying, of Lactobacillus-delbrueckii subsp bulgaricus. J. Ind. Microbiol. 7: 147-149.

Chavarri, F. J., M. Depaz and M. Nunez. 1988. Cryoprotective agents for frozen concentrated starters from non-bitter Streptococcuslactis strains. Biotechnol. Lett. 10: 11-16.

Chen, H., S. W. Chen, C. N. Li and G. W. Shu. 2015a. Response surface optimization of lyoprotectant for Lactobacillus bulgaricus during vacuum freeze-drying. Prep. Biochem. Biotechnol. 45: 463-475.

Chen, H., Y. X. Hui, H. L. Chen, Y. Y. Wu and G. W. Shu. 2015b. Application of plackett-burman design in screening of carbohydrate, prebiotics/alcohols and protein/amino acid for cryoprotectants of Streptococcus thermophilus. Adv. J. Food Sci. Technol. 7: 314-319.

Chmiel, T., M. Kupska, W. Wardencki and J. Namiesnik. 2017. Application of response surface methodology to optimize solid-phase microextraction procedure for chromatographic determination of aroma-active monoterpenes in berries. Food Chem. 221: 1041-1056.

DePaz, R. A., D. A. Dale, C. C. Barnett, J. F. Carpenter, A. L. Gaertner and T. W. Randolph. 2002. Effects of drying methods and additives on the structure, function, and storage stability of subtilisin: Role of protein conformation and molecular mobility. Enzyme Microb. Technol. 31: 765-774.

FAO. and WHO. 2001. Evaluation of Health and Nutritional Properties of Probiotics in Food Including Power Milk with Live Lactic Acid Bacteria, World Health Organization, Geneva.

Fowler, A. and M. Toner. 2005. Cryo-injury and biopreservation. In: Lee, R. C., F. Despa, K. J. Hamann (Eds.), Cell Injury: Mechanisms, Responses, and Repair, Vol. 1066. Annals of the New York Academy of Sciences, New York, pp. 119-135.

Gezginc, Y., I. Akyol, E. Kuley and F. Ozogul. 2013. Biogenic amines formation in Streptococcus thermophilus isolated from homemade natural yogurt. Food Chem. 138: 655-662.

Ghobadi, N., T. Mohammadi, N. Kasiri and M. Kazemimoghadam. 2017. Modified poly(vinyl alcohol)/chitosan blended membranes for isopropanol dehydration via pervaporation: Synthesis optimization and modeling by response surface methodology. J. Appl. Polym. Sci. 134: 44587. DOI: 10.1002/app.44587.

Higl, B., L. Kurtmann, C. U. Carlsen, J. Ratjen, P. Forst, L. H. Skibsted, U. Kulozik and J. Risbo. 2007. Impact of water activity, temperature, and physical state on the storage stability of
Lactobacillus paracasei ssp paracasei freeze-dried in a lactose matrix. Biotechnol. Prog. 23: 794-800.

Huang, L. J., Z. X. Lu and Y. J. Yuan. 2005. Screening of the proper freeze-drying protectants for yoghurt starter. Food Sci. 26: 103107.

Hubalek, Z. 2003. Protectants used in the cryopreservation of microorganisms. Cryobiology. 46: 205-229.

laconelli, C., G. Lemetais, N. Kechaouc, F. Chain, L. G. BermudezHumaran, P. Langella, P. Gervais and L. Beney. 2015. Drying process strongly affects probiotics viability and functionalities. J. Biotechnol. 214: 17-26.

Kurtmann, L., C. U. Carlsen, J. Risbo and L. H. Skibsted. 2009. Storage stability of freeze-dried Lactobacillus acidophilus (La-5) in relation to water activity and presence of oxygen and ascorbate. Cryobiology. 58: 175-180.

Leslie, S. B., E. Israeli, B. Lighthart, J. H. Crowe and L. M. Crowe. 1995. Trehalose and sucrose protect both membranes and proteins in intact bacteria during drying. Appl. Environ. Microbiol. 61: 3592-3597.

Liu, J. Z., L. P. Weng, Q. L. Zhang, H. Xu and L. N. Ji. 2003. Optimization of glucose oxidase production by Aspergillus niger in a benchtop bioreactor using response surface methodology. World J. Microbiol. Biotechnol. 19: 317-323.

Morgan, C. A., N. Herman, P. A. White and G. Vesey. 2006. Preservation of micro-organisms by drying: A review. J. Microbiol. Methods. 66: 183-193.

Ohtake, S., C. Schebor, S. P. Palecek and J. J. Pablo. 2004. Effect of sugar-phosphate mixtures on the stability of DPPC membranes in dehydrated systems. Cryobiology. 48(1): 81-89.

Panoff, J. M., S. Legrand, B. Thammavongs and P. Boutibonnes. 1994. The cold shock response in Lactococcus-lactis subsp lactis. Curr. Microbiol. 29: 213-216.

Passot, S., J. Gautier, F. Jamme, S. Cenard, P. Dumas and F. Fonseca. 2015. Understanding the cryotolerance of lactic acid bacteria using combined synchrotron infrared and fluorescence microscopies. Analyst. 140: 5920-5928.

Peiren, J., A. Hellemans and P. DeVos. 2016. Impact of the freezedrying process on product appearance, residual moisture content, viability, and batch uniformity of freeze-dried bacterial cultures safeguarded at culture collections. Appl. Microbiol. Biotechnol. 100: 6239-6249.

Qin, T., Q. Ma, H. Chen and G. W. Shu. 2013. Effect of four materials including trehalose, soluble starch, raffinose and galactose on survival of Lactobacillus acidophilus during freeze-drying. Adv. Mater. Res. 700: 259-262.

Santivarangkna, C., B. Higl and P. Foerst. 2008. Protection mechanisms of sugars during different stages of preparation process of dried lactic acid starter cultures. Food Microbiol. 25: 429-441.

Schoug, A., J. Olsson, J. Carlfors, J. Schnurer and S. Hakansson. 2006. Freeze-drying of Lactobacillus coryniformis Si3 - effects of sucrose concentration, cell density, and freezing rate on cell survival and thermophysical properties. Cryobiology. 53: 119-127.

Schwab, C., R. Vogel and M. G. Ganzle. 2007. Influence of oligosaccharides on the viability and membrane properties of Lactobacillus reuteri TMW1.106 during freeze-drying. Cryobiology. 55: 108-114.

Selwal, K. K., M. K. Selwal and D. N. Gandhi. 2011. Effect of cryoprotective agents on survival and $\beta$-galactosidase activity of Lactobacillus acidophilus and Streptococcus thermophilus during freeze-drying. Milchwissenschaft milk Sci. Int. 66: 25-28. 
Sohail, A., M. S. Turner, A. Coombes and B. Bhandari. 2013. The viability of Lactobacillus rhamnosus GG and Lactobacillus acidophilus NCFM following double encapsulation in alginate and maltodextrin. Food Bioprocess Technol. 6: 2763-2769.

Stephan, D., A. D. Silva and I. L. Bisutti. 2016. Optimization of a freeze-drying process for the biocontrol agent Pseudomonas spp. and its influence on viability, storability and efficacy. Biol. Control. 94: 74-81.

Teixeira, P. C., M. H. Castro, F. X. Malcata and R. M. Kirby. 1995. Survival of Lactobacillus delbrueckii ssp. bulgaricus following spray-drying. J. Dairy Sci. 78: 1025-1031.
Wang, L. J., X. M.Yu, H. Y. Xu, Z. P. Aguilar and H. Wei. 2016. Effect of skim milk coated inulin-alginate encapsulation beads on viability and gene expression of Lactobacillus plantarum during freeze-drying. Lwt Food Sci. Technol. 68: 8-13.

Yang, C. Z., D. D. Fan, Y. Mi, Y. E. Luo, J. F. Hui and R. Su. 2012. Optimizing the chemical compositions of protective agents for freeze-drying Bifidobacterium longum BIOMA 5920. Chin. J. Chem. Eng. 20: 930-936.

Zhang, J., Z. Zhang, J. Li, W. Li, H. Liu and W. Gu. 2012. Selection and optimization of the cryoprotectants for Streptococcus lactis. China Brew. 31: 147-150. 